\title{
Medical cannabis: Risks related to its indication prior to approval
}

\author{
Francisco J. Appiani, M.D. ${ }^{a}$ and Juan M. Duarte, M.D. ${ }^{a}$
}

\begin{abstract}
In recent years, the interest in medical cannabis prescription has increased significantly. This article provides information about the little scientific basis supporting the prescription of these products for a wide and diverse range of medical conditions. It is critical for any substance to be used in human beings to follow a strict scientific approval protocol, detached from any trend or individual outcome. Before prescribing any drug to human beings, it is necessary to have a clear picture of its uses, especially its safety, which is practically unknown in the case of medical cannabis.

Key words: medical cannabis, cannabinoids, adverse effects, safety, therapeutic uses.
\end{abstract}

http: / / dx.doi.org/10.5546/ aap.2020.eng.64

To cite: Appiani FJ, Duarte JM. Medical cannabis: Risks related to its indication prior to approval. Arch Argent Pediatr 2020;118(1):64-67.

In recent years - and most likely, in future years- the interest in the therapeutic possibilities of cannabinoids has increased significantly. Medical cannabinoids comprise a group of natural

a. Unit of Neuropsychopharmacology, Research and Teaching Board, Hospital de Clínicas José de San Martín, School of Medicine, Buenos Aires, Argentina.

E-mail address:

Francisco J.

Appiani, M.D.:

franciscoappiani@live. com.ar

Funding:

None.

Conflict of interest:

None.

Received: 2-8-2019

Accepted: 8-18-2019 (plant) and synthetic compounds. Natural pharmaceutical products include both nabiximols (containing equal amounts of cannabidiol and tetrahydrocannabinol) and preparations containing only cannabidiol.

C a n n a b i d i o l a n d tetrahydrocannabinol are the most commonly studied active compounds. The latter has a psychoactive effect, whereas the former lacks a direct psychoactive effect and may affect the central nervous system (CNS) by inhibiting the degradation of endocannabinoids.

Synthetic compounds include "nabilone" and "dronabinol" (the synthetic delta-9-THC). Plant compounds may be classified based on their preparation into directly extracted from the plant, compounded preparations, and pharmaceutical industry standard preparations. Natural compounds have been used for recreational and therapeutic purposes for centuries (reports date back to 3000 years ago) and may be associated with abuse, withdrawal, and dependence clinical conditions. ${ }^{1,2}$

The pharmacological effect of this group of compounds takes place through the interaction with the endocannabinoid system, which is made up of receptors located in the CNS and peripheral organs called "CB1" and "CB2." The endocannabinoid system contains endogenous ligands called "endocannabinoids," such as anandamide. ${ }^{2,3}$

To date, drug regulatory agencies, such as the United States Food and Drug Administration (FDA), have approved cannabidiol use for the treatment of two subtypes of refractory epilepsy. According to the United States National Institutes of Health (NIH), a patient is considered refractory to treatment in case of a lack of response to at least four antiepileptic drugs. ${ }^{6}$

Nabilone and dronabinol have been approved for the treatment of nausea and vomiting caused by oncological chemotherapy unresponsive to conventional therapy. Dronabinol is also indicated for the management of weight loss in patients with human immunodeficiency virus (HIV). ${ }^{7}$

However, the number of conditions for which cannabis-based management has been proposed is very extensive. The list includes Parkinson's disease, amyotrophic lateral sclerosis, multiple sclerosis, 
migraine, schizophrenia, posttraumatic stress disorder, eating disorders, Alzheimer's disease, pain, etc. ${ }^{8}$ This is only a brief list of the therapeutic effects that have been described for cannabinoids.

A thorough review of the scientific literature on this topic shows that the scientific evidence supporting the proposed indications is very weak and sometimes even nonexistent. ${ }^{2}$ Anyway, this situation has not overruled the indication of medical cannabinoids. The National Drug, Food and Technology Administration (Administración Nacional de Medicamentos, Alimentos y Tecnología Médica, ANMAT), the Argentine regulatory agency, has approved the prescription under the "compassionate use" label. This indication is done without prior treatment approval, when there is no established therapy for the disease or when indicated treatments have not worked. It is worth noting that, in these patients, the prescriber is solely responsible for the indication. ${ }^{9}$

In turn, the compassionate use of cannabinoids falls under the "orphan drug" condition. This status is applied to a group of drugs used for the management of conditions with a low prevalence in the population. In these cases, government health authorities aid the pharmaceutical industry with the development process so that treatment is financially feasible. This would be a subsequent step to compassionate use and necessary to establish the viability of a treatment. ${ }^{10}$

In Argentina, in 2017, the Congress enacted a law for the promotion of research and regulation to establish the indications and safety profile of cannabis-based products (Law no. 27 350, Medical Use of Cannabis and its Derivatives). ${ }^{11}$ Provincial adherence to this national law has been disparate. ${ }^{12}$

Such necessary national law includes an item that is closely related to the topic of this article that is worth considering. Section h establishes the priority of determining its therapeutic effectiveness, whereas section i establishes that one of the objectives is to know its side effects and determine its safety. ${ }^{11}$ In terms of priority in the development of a treatment, a compound's safety should be established before its effectiveness.

It is known that using a medical treatment before its safety has been demonstrated implies a health risk. Such risk may be reduced, but not completely avoided, with an adequate legislation and, from a practical point of view, through controlled clinical trials. The purpose of this method is, at least in the setting of pharmacology, to assess the effectiveness of a drug and especially establish its safety after it has been tested in cell cultures, animals, and, finally, a large group of people. ${ }^{13}$

Natural cannabinoids are generally used in the form of preparations manufactured under no sanitary controls and for the management of diseases for which safety and effectiveness have not been established. There is no knowledge of the type of cannabinoid content, origin, strength, and safety profile of these products. It is necessary to consider that, for a drug to be used in human beings, it is first necessary to demonstrate its acceptable safety profile. This point, which is key in the implementation of a drug treatment, is dangerously overlooked when prescribing a drug that has not been approved. It is worth noting that the observation of adequate tolerance in individual cases is not enough to conclude that a drug is safe in the short and long term. Products that were assessed in controlled trials in thousands of patients have shown adverse effects and ineffectiveness even after their approval and marketing. ${ }^{10,14}$

It is also advisable to consider that no compound is "inert" or lacks adverse effects from a pharmacological perspective. It is well known that, in certain situations, vital elements, like water and oxygen, may also cause adverse effects, certainly rather severe. ${ }^{15,16}$

It is critical for the scientific community (investigators, primary care physicians, and specialists) to consider the risk of prescribing a product whose components, active ingredient strength, and safety are unknown. Primary care physicians should know in depth the health care situation of medical cannabinoids so as to appropriately provide guidance to face the growing demand for information during everyday office visits.

In relation to the media dissemination by scientists and health disseminators, it would be useful to consider something that may be obvious: the scientific method is based on impartiality and its objective is to find the "truth." 17 In other words, any proper investigator should leave their wishes and prejudices aside because, otherwise, outcomes would be involuntarily -and sometimes, intentionally-biased, thus invalidating them.

If the scientific community does not prove the safety and effectiveness of cannabinoids in an impartial and strict manner, it favors the dissemination of unproven information which, at least, fosters unreal expectations for countless sick 
people. Understandably, either patients or their close family go out looking for a product that mostly lacks adequate production and quality controls. In these cases, the risks include potential contamination and a lack of knowledge of the exact active ingredient strength and dosage to be administered. ${ }^{18}$ It is alarming that, in routine medical practice, no prescribed doses have been established and there is only a suggestion by the handcraft manufacturer.

Cannabinoid use supporters include particularly those people who have observed positive effects in a close relative. This is an understandable situation, but it is not enough to conclude that the compound of interest is safe in the short and long term or that it has demonstrated its effectiveness in a specific medical condition.

At present, for a drug used in frequent conditions to be marketed, it has to be systematically and properly exposed to an average of 3000-5000 individuals. ${ }^{19}$ However, in spite of a strict method implementation, the initial proposed dose may be wrong and major adverse effects may be overlooked, which would be detected once the drug has been marketed. For this reason, in the case of rare diseases, given the smaller availability of information, it is more complex to establish safety and effectiveness. This is one of the major reasons why it is necessary to exercise caution when claiming a drug's effect and safety. ${ }^{20}$

It is also common that only individual positive results get advertised. Reasonably, for the person who experiences such effects, results are undeniable. The problem with this situation is that individual results cannot be extrapolated to the general population. It is well known that what may be therapeutic and safe for a patient, may be unsafe or ineffective for another. ${ }^{21}$

In individual cases, it is difficult to determine the factors responsible for the therapeutic response. The placebo effect should not be ruled out, which has been wrongly associated with a null therapeutic effect. Undoubtedly, it has been determined that cannabis has a very strong effect in relation to the expectations, setting, and circumstances in which the patient uses it. ${ }^{22}$ For this reason, individual reports may serve as guidance but are not enough to arrive to the conclusion of a generalized effect.

In relation to cannabinoids' potential adverse effects, the effect of tetrahydrocannabinol and cannabidiol on schizophrenia may be taken as an example. Multiple scientific studies have demonstrated that, in people at a high risk for schizophrenia, chronic tetrahydrocannabinol use accelerates disease onset. This may have severe effects on the patient because there is a direct relation between early disease onset and overall patient impairment. According to different research studies, tetrahydrocannabinol may be responsible for the harmful effect on the development of schizophrenia given that, if compared to the effect caused by chronic alcohol use during adolescence, the latter would not increase the risk for early schizophrenia development, although it has other known harmful effects. ${ }^{23}$

In addition, some reports suggest that using cannabidiol (the non-psychoactive compound that would have an effect by inhibiting the degradation of endocannabinoids) would be at least equally effective than a compound used regularly for the management of schizophrenia (amisulpride). ${ }^{24}$ So far, regulatory agencies have not endorsed the use of cannabidiol for the management of this disease.

The effect of cannabinoids on schizophrenia is useful to understand the complexity of this topic. On the one side, tetrahydrocannabinol is potentially unsafe; on the other side, cannabidiol may have a potential therapeutic effect.

In sum, it is necessary to raise awareness that the development process of any drug cannot keep abreast of social impulses based on empiricism. The development of a therapeutic compound must follow strict steps that would allow, not unfailingly, to establish the safety profile and risks of its indication in human beings. It is known that trends change and, nowadays, there is a growing interest in cannabinoids. The history of medicine is filled with compounds that claimed to have therapeutic effects -which had not been proved- and that ended up being harmful. Just to name a few, mercury and arsenic were part of the clinical therapeutic armory for centuries, until not so long ago. ${ }^{25}$

Strict studies are required to determine the safety and effectiveness of cannabis derivatives in the most efficient manner possible. If this is not the case, the chance to find the necessary therapeutic tools will be lost and we will only be left with belief-based individual manifestations.

Finally, let us not forget that medical practice should be based on the old maxim "Primum non nocere," that is to say, "First, do no harm." 


\section{REFERENCES}

1. European Monitoring Centre forDrugs and Drug Addiction. Medical use of cannabis and cannabinoids. Luxembourg: Publications Office of the European Union;2018. [Accessed on: July 2019]. Available at: http://www.emcdda. europa.eu / system / files / publications / 10171/20185584_ TD0618186ENN_PDF.pdf.

2. Freeman TP, Hindocha C, Green SF, Bloomfield MA. Medicinal use of cannabis-based products and cannabinoids. BMJ. 2019; 365:11141.

3. Hourani W, AlexanderSP. Cannabinoid ligands, receptors and enzymes: Pharmacological tools and therapeutic potential. Brain Neurosci Adv. 2018; 2:1-8.

4. Food and Drug Administration. FDA approves first drug comprised of an active ingredient derived from marijuana to treat rare, severe forms of epilepsy. 2018. [Accessed on: July 2019]. Available at: https:/ / www.fda.gov/newsevents/ newsroom/pressannouncements/ucm611046.htm.

5. Food and Drug Administration. Drugs@FDA: FDA ApprovedDrugProducts. [Accessed on:July 2019].Available at: https: / / www.accessdata.fda.gov/scripts / cder/daf / index.cfm? event=overview.process\&varApplNo=205525.

6. ClinicalTrials.gov. Epidiolex and Drug Resistant Epilepsy in Children (CBD). [Accessed on: July 2019]. Available at: https: / / clinicaltrials.gov/ ct2/ show / NCT02397863.

7. National Center for Complementary and Integrative Health. Marijuana and Cannabinoids. [Accessed on: July 2019]. Available at: https:/ / nccih.nih.gov/ health/marijuana.

8. Fattore L (ed.). Cannabinoids in neurologic and mental disease. Part 2 and Part 3. San Diego: Elsevier; 2015. Págs.61-421.

9. ANMAT. Uso compasivo para pacientes con epilepsia refractaria a otros tratamientos. 2016. [Accessed on: July 2019]. Availableat:http:/ / www.anmat.gov.ar/comunicados/Uso_ compasivo_aceite_ca\%C3\%B1amo_16-02-16.pdf.

10. European Medicines Agency. Orphan designation: Overview. [Accessed on: July 2019]. Available at: https: / / www.ema.europa.eu/en/human-regulatory/overview / orphan-designation-overview.

11. Ley 27350. Uso Medicinal de la Planta de Cannabis y sus derivados. InfoLeg. Ministerio de Justicia y Derechos Humanos. Buenos Aires, Argentina. March 29 ${ }^{\text {th }}, 2017$
12. Galindez M. Leyes Provinciales en Cannabis Medicinal. [Accessed on: July 2019]. Available at: http://www. cannabismedicinal.com.ar / cannabis-medicinal / regularizacion-seccion/486-leyes-provinciales.

13. Center Watch. Overview of Clinical Trials. What is clinical research? [Accessed on: July 2019]. Available at: https:// www.centerwatch.com/clinical-trials/overview.aspx/. Consultado en julio 2019.

14. Simmons A, Young B. Painfullessons. Nat Rev Drug Discov. 2005; 4(10):800-3.

15. De Leon J, Verghese C, Tracy JI, Josiassen RC, et al. Polydipsia and water intoxication in psychiatric patients: a review of the epidemiological literature. Biol Psychiatry. 1994; 35(6):408-19.

16. Fisher AB. Oxygen therapy: side effects and toxicity. Am Rev Respir Dis. 1980; 122(5 Pt 2):61-9.

17. RaoDB.Scientificattitude. New Delhi:Discovery Publishing House; 2003.

18. Hazekamp A. The Trouble with CBD Oil. Med Cannabis Cannabinoids. 2018; 1(1):65-72.

19. Appiani F. Actualización en el tratamiento psicofarmacológico en las embarazadas. In: Appiani F. Efectos adversos y seguridad en Psicofármacos. Buenos Aires: Akadia; 2009.Págs.21-33.

20. Stricker BH, Psaty BM. Detection, verification, and quantification of adverse drug reactions. BMJ. 2004; 329(7456):44-7.

21. Appiani F. Actualización clínica y farmacológica del sistema de metabolismo microsomal P450. In: Appiani F. Efectos adversos y seguridad en Psicofármacos. Buenos Aires: Akadia; 2009.Págs.97-108.

22. Appiani F. Aspectos clínicos y neurobiológicos del efecto placebo. In: Appiani F. Efectos adversos y seguridad en Psicofármacos. Buenos Aires: Akadia; 2009.Págs.115-21.

23. Large M, Sharma S, Compton MT, Slade T, et al. Cannabis use and earlier onset of psychosis: a systematic metaanalysis. Arch Gen Psychiatry. 2011; 68(6):555-61.

24. Leweke FM, Piomelli D, Pahlisch F, Muhl D, et al. Cannabidiol enhances anandamide signaling and alleviates psychotic symptoms of schizophrenia. Transl Psychiatry. 2012; 2:e94.

25. Warkany J. Acrodynia-postmortem of a disease. Am J Dis Child. 1966; 112(2):147-56. 